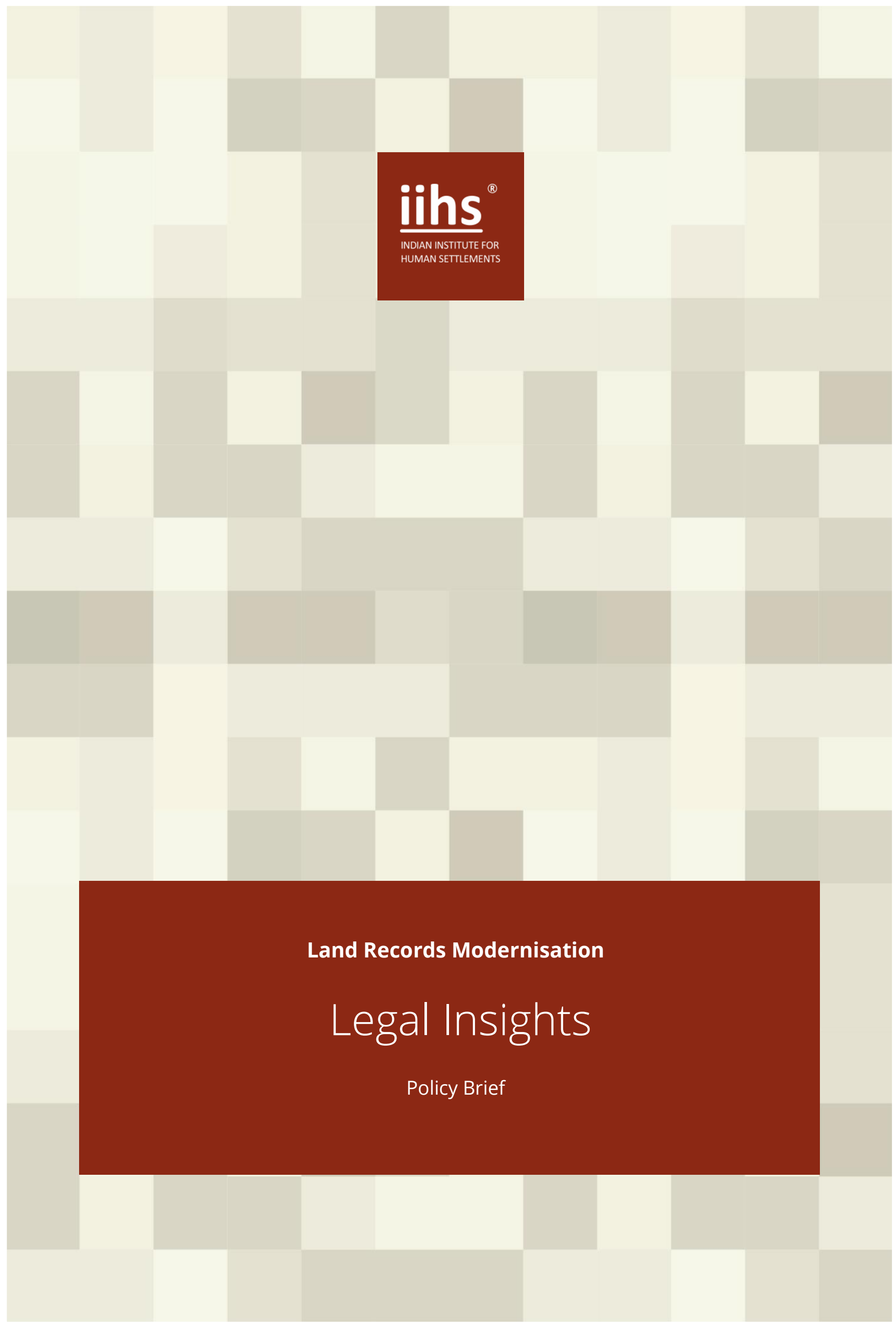




\section{LAND RECORDS MODERNISATION: LEGAL INSIGHTS}

\section{Background}

There are an estimated 24 million cases (DoLR, 2011) ${ }^{\mathrm{i}}$ pertaining to land disputes pending before courts in India. This may well be a conservative estimate. Litigation around land is multi-dimensional and in multiple courts, ranging from disputes regarding boundaries, inadequate permissions, unauthorised constructions, change of land use permissions, contractual obligations, fraudulent registrations, incomplete mutations, non-updated spatial information, tenurial questions, partition matters, common areas questions, customary rights claims, land acquisition claims, notification and denotification questions and so on. It has been repeatedly argued that having an accurate comprehensive up-to-date land record system, along various parameters such as ownership, possession, classification, extent and encumbrances, which is real-time, mapped and shared across various departments and easily accessible to the common citizen, would be of value in obviating disputes around land. As such, one of the critical outcomes for any land records modernisation effort should be reduction in litigation rates. The legal issues as such cannot be separated from the larger political economy questions within which land is located in India.

Various suggestions have been made to make records reform possible. Some efforts in the past have focused on a Model Titling Bill (2011), from the Centre, advocating the three Torrens principles of 'mirror', 'curtain' and indemnification for conclusive titling. However, for a variety of reasons, the Model Bill has had no traction among the states. An important lesson from past endeavours is to understand and appreciate particular good practices among states and the challenges faced by them in order to arrive at a more comprehensive understanding of the realities on the ground and keeping political economy at the heart of the enterprise. This incremental approach to create a more comprehensive land records system, focused on central incentivisation of outcomes, needs to acknowledge the diversity of state laws and practices, within a decentralised federal system. A one-size-fits-all approach is unlikely to work. Some attention is also needed on questions of access, particularly among landless in rural areas, as well as those pertaining to recording of transactions in rental markets and on matters of tenurial security in informal settlements, especially in urban areas.

For instance, "According to National Sample Survey Organisation (NSSO) data (2003-04), about 41.63 per cent of households do not own land other than homestead. The data also shows that while one third of the households are landless, those near to landlessness add up one third more. The next 20 per cent hold less than one hectare. In other words, 60 per cent of the country's population has right over only five per cent of country's land; whereas 10 per cent of the population has control over 55 per cent of the land" (DoLR, 2013) ii.

Similarly, estimates of the number of people in Indian cities living in 'slums' (usually unauthorised settlements of the poor) vary from 25\% to more than 50 per cent (MoHUPA, 2013; UN Habitat, 2003) iii. Further, informal sectors contribute between 40 to 60 per cent of the urban GDP as per estimates (ILO, 2002; SEWA 2009; Kolli, 2011) ${ }^{\text {iv }}$.

This reality calls for a more nuanced approach, keeping in mind the needs of all stakeholders, in various states, rather than a rigid focus on titling alone. Such an approach could also draw upon and build on existing municipal endeavours aimed at improving tax collections, where ownership is not as significant as the enumeration of property and the incentives are largely to augment tax revenues than to arrive an undisputed ownership, which is usually fraught with litigation.

\section{Constitutional Position on Land Records}

The states in India have powers to legislate on various matters under List II of the Constitution relating to 'land revenue, including the assessment and collection of revenue, the maintenance of land records, survey for revenue purposes, and records of rights, and alienation of revenues' (Entry 45); and 'rights in or over land, land tenures including the relation of landlord and tenant, and the collection of rents; transfer and alienation of agricultural land, land improvement and agricultural loans; colonisation' (Entry 
18). This clearly indicates that the states are the primary actors in the process, and the Revenue Department has been the primary actor within the states. At the same time, with increasing urbanisation, land record information rests within multiple silos, such as development authorities, town planning bodies, municipalities and particular state parastatals.

Land revenue Acts (under which the land records modernisation efforts of various states derive their basis) and urban and planning legislations, for example, are within the jurisdiction of states and not the Union Government. At the same time, as under the Concurrent List powers (to both union and states), a number of central legislations also prevail on matters that have a direct relationship with land records: the Registration Act, 1908, the Stamp Act, 1899, the Transfer of Property Act, 1882, the Evidence Act, 1872 and so on, which are also of colonial origins, while undergoing subsequent revisions. Some of these legislations are also further adapted and amended at respective state levels.

\section{Presumptive and not Conclusive Deeds-based System}

In Suraj Bhan vs Financial Commissioner and others (2007) (6) 186), the Supreme Court held, inter alia, that "it is well settled that an entry in revenue records does not confer title on a person whose name appears in the record of rights. It is settled law that entries in the revenue records or Jamabandi have only 'fiscal purpose' i.e. payment of land revenue and no ownership is conferred on the basis of such entries. So far as the title is concerned, it can only be decided by a competent Civil Court."

For instance, the Registration Act, 1908, mandates compulsory registration of a sale deed on land. However, it does not require the registration authorities to verify the history of the land or its ownership and encumbrances from the seller. The Indian Registration Act, 1908 is the basis for the system of registration of instruments i.e. it is based on a deeds-based registration system where the deed serves as evidence of the transaction having taken place and not as proof of title.

Similarly, the Transfer of Property Act, 1882, identifies the processes involved with property transactions but does not contain references to verification of the previous legal status of the seller. This is primarily based on the principle of 'caveat emptor' or 'let the buyer beware'. The notion of presumption also applies in 'benami' transactions, where the transferee/purchaser is not necessarily the financier of the transaction. Those transactions are presumed to be not 'benami' unless proven otherwise.

India largely uses a deeds-based land registration system, where deeds are registered as proof of a transaction, unlike some other parts of the world that use a title-based system. Title is not conferred directly, but is presumptive, derived from the registered deeds and documents. Recording of a deed does not serve as proof that the parties have a legal right to enter into a particular transaction. In land and property transactions, a deeds-based system indexes the names of the involved parties, rather than the parcel of land, and cadastral maps are generally not used.

In addition, records for revenue and registration systems exist in parallel in India. A land transaction registered under the Registration Act, 1908 is technically supposed to be updated within the revenue Record of Rights (RoR), which does not necessarily happen. To add to the complication, certain transactions which may be entered in the RoR do not require registration under the Registration Act, 1908. This has also led to divergence between the two records systems. 
Section 17 of the Registration Act, 1908, although mandating compulsory registration of a sale deed on land, does not require the registration authorities to verify the history of the land or its ownership and encumbrances from the seller. Under Section 18 of the Registration Act, 1908, certain documents do not require mandatory registration. This creates loopholes for transactional malfeasance. First, Power of Attorneys (POA) do not have to be registered. They create transfer of property (at a lower stamp duty rate than compulsorily registerable deeds) and has often lead to illegal transactions and litigation disputes. While the Registration Amendment Bill, 2013 has mandated compulsory registration of POA, the Bill is still pending in the Rajya Sabha. Other such documents that currently do not require mandatory registration include lease deeds not exceeding one year, and agreements relating to creation of mortgages by deposit of title deeds. Under the pending Registration Amendment Bill, 2013, if passed by Parliament, these documents will also require compulsory registration.

As per Section 35 of the Stamp Act, 1899, instruments that are not duly stamped are not admissible as evidence, nor can they be registered by a public official, which is pertinent for property transactions. Similarly, a failure to register under the Registration Act, 1908 results in such document being inadmissible as evidence of the transaction having taken place.

The Indian Evidence Act, 1872, reaffirms this presumption with respect to registered documents. While Sections 21 and 22 of the Registration Act, 1908 provide legitimacy to the survey and settlement process, maps and surveys which have the potential of providing clarity on boundaries and area-specific details do not require mandatory registration along with property documents even though the Evidence Act 1882 recognises details in maps as facts. ${ }^{v}$

\section{Need for Legal Changes Incorporating Technology Modernisation}

Legal Status of Electronic Records: The computerisation of land records being implemented under the Digital India Land Records Modernisation Programme (DILRMP), and the database of such records (such as the 'nakal Jamabandi', the records of mutations and other transactions in the computerised record) shall be deemed to have the status of electronic records as per the Information Technology Act, 2000. The authenticity of such computerised records will be subject to the checks and protocols under the Indian Evidence Act, 1872 as and when they are produced by way of electronic evidence in a court of law. The Information Technology (IT) Act, 2000 created new definitions of "data", "electronic record", and "computer". According to section 2(1) (t) of the IT Act, an electronic record is "data, record or data generated, image or sound stored, received or sent in an electronic form or micro film or computer generated micro fiche".

The Indian Evidence Act, 1882 has been amended to recognise electronic records as having evidentiary value in addition to conferring a presumption as to the correctness of electronic records that are over five years old.vi There are also evidentiary rules for electronic records in the Evidence Act, 1872: section 65A and section 65B.

State-level amendments: Some states, such as Andhra Pradesh and Karnataka, have amended their state legislations on matters relating to 'registration of documents by electronic means'. Manual records have been invalidated through amendment to Karnataka Land Revenue Rules, 1964 in 2000 and appropriate government orders and any changes to the record of rights are only supposed to happen through online mutation application (BHOOMI) vii. The Registration (Karnataka Amendment) Act, 2000 laid the foundation for the introduction of electronic records in the state. In light of legislative changes at the Centre, with respect to technology laws, a majority of states have updated their land revenue codes to include electronic records.

In Haryana, for example, it would be useful if the Registration Act (as applicable in Haryana) mandates that the Haryana Registration Information System (HARIS) (registration database) pre-checks the Haryana Land Record Information System (HALRIS) (land records database) for information on ownership, prior to registration. It has been seen in certain areas, for example, that the Registration- 
Mutation Bridge is only one-way. During registration HARIS connects to HALRIS, and once the sale deed is registered, the remarks column in the RoR mentions 'mutation pending' but this does not trigger an automatic mutation application. Instead, a customer has to approach the concerned Patwari in the HALRIS section and pay a mutation fees to get the process started.

In Himachal Pradesh, for example, there are instances where a land parcel is in an abadi area, where individual ownership is not recorded, and hence mutation is not carried out.

Madhya Pradesh has brought in several key changes to the central Registration Actviii, such as making PoA compulsorily registerable and making it mandatory to produce a map and a photograph of the property before registration of sale deed. Maharashtra has initiated an online registration through use of Aadhar cards, especially in cases of lease and license, first sale of developer plots and allotments by state housing development agency.

However, issues persist on verification, attestation, digital signature and public access. The Right to Information Act, 2005 has become critical for the purpose of viewing public records and public access to land records. The Registration Amendment Bill, 2013 has sought to bring about more transparency by making all records available for public inspection.

Certification or attestation however is still necessary. Questions of e-signature are dealt with separately as part of Public Key Infrastructure (PKI) under the Indian IT Act, 2000. The Information and Technology Act, 2000 provides legal recognition to electronic data and digital signatures (PKI). PKI is necessary to admit such a document in a court of law. Technological changes necessitated in transitioning to an esignature regime need further exploration. While electronic records have been conferred with legal/evidentiary status, it does not change the otherwise presumptive nature of various electronic records maintained at state levels. These structural questions of presumptive title and deeds-based systems continue.

As such, technology transitions and modernisation efforts in land record management require assessments in terms of the following:

- Legal processes of due-diligence within the land records management system;

- Legal sanctity through protocols to reconcile and address discrepancies between textual and spatial data in the land records, as well as with new data being mapped and collected via surveys; and

- Procedural systems being put in place to arbitrate claims and disputes, as they arise.

In most states throughout the country, there is need to incorporate legal dimensions in the ongoing exercises, including creating adequate statutory basis so that the initiatives have full legal sanctity thereby creating a greater degree of clarity in protocols before the courts. This becomes especially relevant in relation to new technology initiatives, spatial and surveying techniques as well as digitisation.

\section{New Disputes Arising From Land Modernisation Efforts}

1. Legal reconciliation:

o Digitisation of the Mussavis (field maps) involves the reconciliation of three sets of records: textual revenue records, spatial revenue records and satellite image data. Practices being followed to reconcile the differences between the three sets of data are being validated primarily through the intervention of revenue functionaries but do not have requisite state-level institutional protocols. It is not clear if this process would be legally upheld by the courts in case of disputes involving various claims of legitimacy.

o A major source of disputes in technology initiatives of the NRLMP is that of data mismatch, i.e., between the data that is obtained technologically (extent of area of landholdings ascertained through geo-spatial technology) and the data that is contained within the ROR and Mussavis. 
o Another source of disputes is the mismatch between the ROR and Mussavis themselves, the resolution of such disputes is subject to the procedures, courts and authorities.

o Disputes arise due to variation between the legacy record and the new record created after settlement.

2. Processes of land demarcation, survey, consolidation, redistribution and acquisition are fraught with disputes and such disputes rest upon the entries of the RoR (legitimate, while not always updated or accurate).

\section{Larger Tenure and Property Rights Issues}

There seems to be inadequate acknowledgement, on the part of current land records modernisation efforts, of the conceptual categories and tools regarding tenure and property. This is also linked to how claims are adjudicated in courts. The debate on title and tenure serves as the contextual background for questions of presumptive and conclusive title, deeds and title-based systems, within which the new trajectory of land records modernisation efforts is playing out.

The discussion on legal aspects of tenure is relevant for two reasons:

First, given the great deal of informality (and multiple categories of rights) within tenurial arrangements in India, the absence of legal recognition often adversely affects security of tenure. Affordable housing is a serious distributive problem in Indian cities that requires a wider understanding of tenurial relations. The strict legal emphasis has generally been on property rights in relation to ownership-specific, and at times possession-related, arrangements/relationships without considering other informal/non-formal interests that may exist on land. The absence of security of tenure and the lack of legal recognition of rights creates the threat of eviction for vulnerable groups.

In such context, every land records modernisation effort faces a particular dilemma. On the one hand, it could, if it chooses to, record such claims under 'possession' particulars. However, it could also choose to ignore such claims, in the absence of an express 'regularisation' order from the Executive, or a directive to that effect in a particular case from the courts.

This creates a difficult situation as to whether to record de facto details as they exist on the ground or to exclude whole groups of settlements and land use from the records, by focusing only on questions of ownership, and that too where presumptive, and not conclusive title documents are otherwise available. A land records system cannot be altogether impervious to such detail, since the choosing of a particular subject and manner of recording also has a future impact, not just on the land use, but also on the actual lives of people, especially informal settlements. Recording such use may provide legitimation of possession, but if a records regime focuses only on title, it would leave out large parts of land and populations living on such land, on the ground that there is no clarity of title, that use of such lands is 'illegal', and that transferability or the nature of encumbrances etc. on such property present particular difficulties of interpretation and implementation.

\section{Inadequacy of Model Titling Bill 2011}

It is pertinent here to mention the Model Land Titling Bill, 2011, which was advocated as a solution to the problem of ensuring conclusive clarity in title. The Model Land Titling Bill, drawn up by the Centre as a template which state governments could adopt (since these aspects come under the State List), recommends a shift to conclusive titling through a simple process of a government notification.

The model Bill advocates an altogether new institutional framework comprising a Land Titling Authority, Title Registration Officers, a Land Titling Tribunal and a Land Titling Fund. However, this is only a model for states to adopt should they choose to, since the subject of land records as per the Indian Constitution is a matter for states to decide. 
So far, there is no traction from the states on this initiative, partly because the Model Bill does not find a way to resolve the incremental difficulties that have arisen in land records modernisation efforts. In particular, the Model Bill does not clarify the processes of due-diligence and verification processes that new institutions might follow and the practices they might adopt to implement and maintain the 'curtain' and 'mirror' principles.

Conclusive Title through a model Bill is no easy panacea. Since the Judiciary assumes an indispensable role in upholding claims in India, a shift from presumptive to conclusive titling needs to be understood in terms of legal processes, structures and verification protocols involved in judicial determinations. Despite detailed guidelines to improve operational efficiencies in land records management, current initiatives lack institutional and legal process details, beyond the conception of new meta-institutions, including new titling authorities.

The Model Land Titling Bill, 2011 drafted by the then Central Government was an attempt to create a template for states to establish a system of conclusive titles. It is a 'model' and not an actual bill since 'records of rights' come under the State List and only states can legislate on such issues. It attempted to create a separate de novo Land Titling Authority (LTA) where existing functionaries of the Survey, Settlement and Land Records (SSLR) and Registration departments would report to the LTA. Relevant Title Registration Officers (TRO), were to be made in charge of creating the documentary basis for establishing the conclusiveness of title. Separate Land Titling Tribunals (LTT) were also proposed to be created. Significantly, suits before the Civil Courts were to be barred if these authorities were in place.

The overall attempt in this Model template was to create a system of title registration through Government notification. It tried to tie registration of title to the particular property parcel, and thereby accord conclusiveness of title, if there was no objection to the property recorded for three years. A new system based on an electronic 'Register of Titles' was to be put in place, rather than existing formats such as the rural Record of Rights, Tenancy and Crops (RTCs) and the urban Property Cards. However, there seem to be no details on rights that would be recorded in the Register or the format of property papers that would be generated. It is mentioned that the new Register would incorporate details from existing urban and rural records. However, the procedure for migrating data of RTCs and urban PR cards is not detailed, especially with regard to disputes and problems that current land record modernisation efforts across states are already encountering. The new proposed Land Titling Authority was to be given significant discretionary powers, to decide on which titles are 'clear' enough to be registered. Significantly, there is no explicit mention of a survey function to materialise the 'mirror' principle of the Torrens system.

The 'Model Bill' provides a list of alternate claims that the LTT would look into, including leasehold rights, possession, easements, customary rights, public rights, mines and mineral rights, franchises, nonstatutory rights (for example, related to sea or river embankments), power of attorney based claims, bankruptcy issues, recovery of statutory duties, levies, taxes, encumbrances, etc. A national or state-level consolidated fund is mentioned as a possible financing source for the new LTA, without details regarding the basis on which this fund would be constituted.

Rajasthan Legislative Assembly had passed Rajasthan Urban Land (Certification of Titles) Act 2016 on titling in urban areas. The Act recommends a voluntary process for owners to submit the paperwork necessary to get a provisional land title certificate. If undisputed for three years, a provisional certificate may be changed into a permanent certificate.

The model titling template does not seem to have gained much traction among the states in India, even as title certification system has been one of the optional reforms for central funding suggested under the Jawaharlal Nehru National Urban Renewal Mission. An incremental strategy has been to ensure comprehensiveness rather than conclusive titles, which is itself based on availability of correct land records which are not contested. Incremental efforts towards creating more comprehensive land records, along with attendant inter-institutional interfaces and particular legal challenges, need to be addressed. The efficacy of evidence and verification protocols would have a direct bearing on whether or not the 
Judiciary chooses to recognise such conclusiveness in future. Barring litigation is itself fraught with legal issues.

The enormity of the task, the proposed creation of de novo authorities and officers (in place of the existing system), the inadequacy of records, and the lack of adequate attention paid in the Model Bill to existing issues of land records management, are some of the reasons why this proposal did not find traction among state governments. Conclusive titling was seen as a panacea, to be carried out through a single stroke, without necessarily an appreciation of the processes and problems associated with current efforts and the incremental steps that were being taken. The problem of obtaining 'results' in the form of clear titles is anyway of the states, and Central funding of a parallel machinery for adjudicating disputes and maintenance of the record creates additional inefficiencies.

\section{ANNEX 3: LEGAL INSIGHTS FROM STUDY STATES}

\section{Some Additional Legal Insights from Select States}

The sections below highlight some of the main legal issues and points relevant to particular states within the study.

\section{i. $\quad$ Karnataka}

Legislations in relation to land records in the state can be broadly categorised into three broad phases. The first phase focused on issues such as revenue, land reforms, tenancy, and the establishment of urban local bodies. The second phase, which began in the 1970s, marks the establishment of various urban development authorities with a larger emphasis on planning. In the third phase, post-liberalisation, the focus has been on decentralisation (under the $73^{\text {rd }}$ and $74^{\text {th }}$ Amendments) as well as e-governance, whereby electronic records have been given legal statusix. In relation to land records, the state has made it mandatory for a form $11 \mathrm{E}$ sketch to be made before mutation may be initiated in order to corroborate textual and spatial records.

Despite these developments, the state has failed to include such planning classifications, conversion and changes in land use details within records, enhancing difficulties especially within urban and peri-urban areas. In terms of litigation within the urban areas, planning related disputes constitute a large share. Issues such as denotification of areas, the Akrama Sakrama regularisation enactment etc. are some examples within the state. The conversion of agricultural land to non-agricultural assumes particular relevance in light of growing urbanisation in the state wherein procedures as laid down under the law are often not adhered to, leading to disputed claims over the title and nature of land.

\section{ii. Haryana}

There are two sets of legislations within the state. The first consists of those laws enacted prior to 1966 applicable to the entire state of Punjab, of which Haryana was a part. The second consists of those enacted post 1966, in the newly formed state of Haryana which was conferred with legislative powers as a state.

Haryana is of particular relevance in terms of various aspects from a legal standpoint. First, the East Punjab Holdings (Consolidation and Prevention of Fragmentation) Act, 1948 mandated that landholdings be consolidated in the state. This has had a profound impact on land records management in the state whereby rectangular plots have made sub-division or amalgamation easier in addition to ensuring continual surveys to be undertaken. Second, the prevalence of a shares system of joint land holdings is predominant. The partition of land holdings while legally a viable option, is often not pursued as a course of action due to the perception of it being a dispute-ridden and time-consuming process. This often results in demarcation disputes. Third, the legislative provisions in the state have not kept pace with de facto developments on the ground. The state widely uses discretion and innovates through Standing Orders, memos and notifications. However, these techniques are also open to further judicial review and litigation. This practice is often used within the areas where the real estate sector in Haryana (parts of the 
National Capital Region-NCR) have witnessed high real estate growth rates. The processes of conversion for instance are carried out in this manner and is a cause for litigation. Further, as an example of the legal reliance on records, the courts in the state have taken up issues of common lands and possession based on entries in the Jamabandi. ${ }^{\mathrm{x}}$

The state of Himachal Pradesh, after various stages of amalgamation and reorganisation, attained statehood in 1971. It is unique in its topography marked by hilly terrain and predominance of forest areas. As a result, the legal concerns in the state differ slightly from other states. In relation to land records in the state, a point of relevance relates to the legal sanctity accorded to various other records (other than the Jamabandi) such as the Wajib ul Urz and the Shajra Nasb. These contain records of various rights and entitlements which may be undocumented/informal in other states.

A main legal issue in the state relates to the restrictions imposed by the Himachal Pradesh Tenancy and Land Reforms Act, 1972 which restricts the transfer of land to "any person who is not an agriculturalist from the state" (Revenue Department, GoHP, n.d) xi without state permission. Current governmental efforts have proposed amendments/revisions (process, domicile, non-agriculturalist related) in the law in order to permit developers and industries to enter into the state. The protection of forest rights is another legal concern in the state. Himachal Pradesh, via its legislative enactments, has ensured that relevant forest use/access rights be included with land records in various forms. In addition, it follows strict rules in relation to the conversion/transactions within these areas.

The main disputes throughout the state deal with demarcation, partition by metes and bounds and multiple sale of shares, while urban-specific disputes include unauthorised constructions, encroachments and planning permissions.

iv. Gujarat

Gujarat has engaged in preparation of functionary-specific manuals which combine roles of different officers all concerned departments. The Prant Officer Manual (April 2006), Mamlatdar Manual (April 2007), Collector Manual (April 2008), and Talati Manual (December 2008) act as a guiding framework for respective officials. In addition, the Resurvey Manual (April 2012) includes details of the resurvey process, as well as protocols on how various issues faced during the resurvey are to be addressed.

The dispute resolution structure in Gujarat includes Special Secretary Revenue Department (dispute), Gujarat Revenue Tribunal, Civil courts, and the High court. Special Secretary Revenue Department (dispute) (SSRD) has been allocated as the appellate authority with revisional review over the decisions of the revenue officers at the district level. It chiefly deals with appeals against orders of Collectors and hence would be dealing with various disputes that pertain to revenue and land administration. 
i'Success Stories on the NLRMP', NIC,Deity,MCIT,GOI and DOLR,MORD,GOI, n.d. . (Estimate derived from source, based on $80 \%$ of around 30 million court cases pending in India in 2014)

ii Draft National Land Reforms Policy, 2013, DoLR, Government of India

iii 'The Challenge of Slums', Global Report on Human Settlements, UNHABITAT, 2003

iv ILO (2002). Women and Men in the Informal Economy: A Statistical Picture. Retrieved from:

http://www.ilo.org/dyn/infoecon/docs/441/F596332090/women\%20and\%20men\%20stat\%20picture.pdf; SEWA (2009). Building

Membership-Based Organisations of Informal Women Workers. Indore Management Journal, 1(2), 91-95. Retrieved from:

http://www.iimidr.ac.in/iimi/images/IMJ/Volume1_Issue2/Building\%20Membership-

Based\%20Organisations\%200f\%20Informal\%20Women\%20Workers.pdf; Kolli,R. 2011. 'Measuring the Trade Sector in the National Accounts of India', Review of Income and Wealth, Series 57, Special Issue, May 2011.

v Section 36, Indian Evidence Act, 1872

vi Section 90A, read with Section 35 of the Evidence Act, 1882

vii DoLR, 2012, Success Stories on National Land Records Modernisation Programme. Accessed at http://dolr.nic.in/dolr/downloads/pdfs/revenue_ministers_document.pdf on 11/04/2014.

viii Pending for GoI approval, as of $26^{\text {th }}$ Feb 2015

ix The Information Technology Act, 2000 and the Registration (Karnataka) Amendment Act, 2011 are examples.

x Jai Singh vs State of Haryana, (2003) 134 PLR 658

xi Compendium of Rules, Instructions and Clarifications relating to Section 118 of the H.P. Tenancy \& Land Reforms Act, 1972, Revenue Department, Government of Himachal Pradesh. 